\title{
DESENVOLVIMENTO SUSTENTÁVEL E OS MUNICÍPIOS: UMA ANÁLISE SOB A PERSPECTIVA DOS OBJETIVOS DO DESENVOLVIMENTO SUSTENTÁ VEL E DA LEI No 13.493/17 (PIV - PRODUTO INTERNO VERDE)
}

Meilyng Leone Oliveira ${ }^{1}$

\section{RESUMO}

O presente estudo tem como eixo principal o Desenvolvimento Sustentável e de que modo as atividades públicas municipais podem ser impactantes em termos de responsabilidade socioambiental. Assim, realiza-se a análise dos documentos internacionais que tratam sobre o tema, principalmente o A/RES/70/1, da ONU (Organização das Nações Unidas) e a atual "agenda 2030" (2016-2030), que estabeleceu os ODS (Objetivos do Desenvolvimento Sustentável), composto por 17 (dezessete) objetivos e 169 (cento e sessenta e nove) metas, tendo como finalidade a promoção e fomento da sustentabilidade. Ainda, analisa-se a Lei Federal $n^{\mathbf{0}}$ 13.493/17, que estabelece o Produto Interno Verde (PIV), em cujo cálculo será considerado o patrimônio ecológico nacional. Os objetivos representam um plano ambicioso para acabar com a pobreza, reduzir as desigualdades e combater as mudanças do clima. Considerando que até o ano de 2030, segundo o relatório da ONU-Habitat, dois terços da população devem viver em cidades, objetiva-se com o presente estudo demonstrar de que forma as ações locais, no âmbito municipal, são potencialmente relevantes no contexto local e global para a efetivação do desenvolvimento sustentável, e, consequentemente, à garantia do acesso ao meio ambiente ecologicamente equilibrado, para as presentes e futuras gerações.

Palavras-chave: Direito Ambiental; Democracia; Desenvolvimento Sustentável; Produto Interno Verde (PIV); Direito das cidades.

\section{SUSTAINABLE DEVELOPMENT AND MUNICIPALITIES: AN ANALYSIS UNDER THE PERSPECTIVE OF SUSTAINABLE DEVELOPMENT GOALS AND LAW 13.493/17 (PIV - GREEN DOMESTIC PRODUCT)}

\begin{abstract}
The present study focuses on Sustainable Development and how municipal public activities can be impacting in terms of social and environmental responsibility. Thus, an analysis of the international documents dealing with the subject, especially A / RES / 70/1, of the United Nations (Organization of the United Nations) and the current "2030 agenda" (2016-2030), which established the ODS (Sustainable Development Objectives), consisting of 17 (seventeen) objectives and 169 (one hundred and sixty-nine) goals, with the purpose of promoting and fostering sustainability. Also, Federal Law 13493/17, which establishes the Green Internal Product (PIV), is analyzed, in the calculation of which will be considered the national ecological patrimony. The goals represent an ambitious plan to end poverty, reduce inequalities and combat climate change. Considering that by the year 2030, according to the UN-HABITAT report, two-thirds of the population should live in cities, the aim of this study is to demonstrate how local actions at the municipal level are potentially relevant in the local context sustainable development, and consequently guaranteeing access to the ecologically balanced environment for present and future generations.
\end{abstract}

\footnotetext{
${ }^{1}$ Advogada. Pedagoga. Doutoranda em Direito Ambiental Internacional (com bolsa CAPES). Mestre em Direito Ambiental. Ambos pela Universidade Católica de Santos (UNISANTOS). Coordenadora do Curso de direito da faculdade Unibr. Professora Universitária. Diretora Escolar. MBA em Direito Empresarial pela Fundação Getúlio Vargas (FGV). Presidente da Comissão de Cultura e Eventos da 44a Subseção da OAB-SP.
} 
Keywords: Environmental Law; Democracy; Sustainable Development; Green domestic product (GDP); Law of cities.

\section{INTRODUÇÃO}

A busca pelo desenvolvimento sustentável é multifacetada - não pode depender de um único fator. Muitos parâmetros sociais são importantes, como, por exemplo, a governança, as formas de organização econômica e de participação dos cidadãos. Enquanto o mundo inicia a implementação da Agenda 2030 para o Desenvolvimento Sustentável e seus 17 objetivos, $13 \%$ por da população mundial ainda vive em extrema pobreza, 800 milhões de pessoas passam fome e 2,4 bilhões não têm acesso a saneamento básico.

Os Objetivos do Desenvolvimento Sustentável, denominados a partir deste de ponto por ODS, são construídos a partir das conquistas dos Objetivos do Desenvolvimento do Milênio, que produziram o mais bem-sucedido movimento de combate à pobreza na história durante o período de 2000 a 2015. Em 2015, 6,6 bilhões de pessoas, ou 91\% da população global, usaram uma fonte melhorada de água potável, comparados a 82\% em 2000. Além disso, a assistência oficial ao desenvolvimento totalizou 131,6 bilhões de dólares em 2015, aumento de 6,9\% em termos reais na comparação com 2014 e representa o nível mais alto já alcançado. A estimativa é de que 5,9 milhões de crianças com menos de 5 anos morreram em 2015, a maior parte por causas evitáveis, e 216 mulheres morreram no parto a cada 100 mil nascimentos. Em 2013, 59 milhões de crianças em idade escolar estavam fora da escola e $26 \%$ das mulheres com idade entre 20 e 24 anos se casaram antes de completar 18 anos.Em 2015, estimadas 663 milhões de pessoas ainda usavam fontes de água insegura. Em 2012, 1,1 bilhão de pessoas ainda estavam sem acesso a esse serviço essencial (UNITED NATIONS, 2016, p. $6)$.

A afirmação de que dois terços da população mundial devem viver em cidades até 2030, de acordo com os dados do relatório da ONU-Habitat, a urbanização fornece a maior oportunidade, e também responsabilidade, para alcance dos Objetivos de Desenvolvimento Sustentável, principalmente em relação à meta de número 11, que propõe tornar as cidades e os assentamentos humanos inclusivos, seguros, resilientes e sustentáveis.

Nesse contexto, a governança detém um papel crucial na consecução desses objetivos, em no cenário jurídico brasileiro, o município possui grande encargo e atribuições, o que nos leva a perceber da importância das escolhas realizadas no âmbito local. 
Governança urbana pode ser definida como as várias maneiras em que as instituições e indivíduos estão organizados na gestão diária de uma cidade, e os processos utilizados para realizar eficazmente a agenda de desenvolvimento de uma cidade, de curto e longo prazo. Governança é o ambiente favorável que exige quadros legais adequados, processos políticos e uma gestão administrativa eficiente, bem como mecanismos, orientações e ferramentas para permitir que o governo local para responder às necessidades dos cidadãos. Na verdade, é um processo de tomada de decisão envolvendo vários atores com diferentes prioridades para garantir que as normas são estabelecidas e onde o desenvolvimento é alcançado e serviços são prestados aplicam.

Portanto, é um processo contínuo que indica o sucesso de um sistema de cidade. Os governos locais têm proximidade, legitimidade e escala na maioria dos países do mundo, para serem eleitos diretamente pelos cidadãos, tornando-se a esfera de governo mais próxima da participação da população nos assuntos públicos. A governança urbana reside principalmente nas mãos dos governos locais, que têm adjacência para traduzir os princípios da boa governança e dirigir com eficácia para desenvolver uma cidade que garanta a cidadania urbana equitativa. No contexto de insegurança e de conflito, os governos locais também têm o potencial para construir relações positivas entre o Estado e a sociedade, devendo se conectar com os cidadãos para assegurar que os princípios da cidadania serão preservados. Um governo local deve conduzir uma gestão responsável, sustentável e transparente.

\section{Sobre os Objetivos do Desenvolvimento Sustentável, a Agenda 2030 e a COP-21}

Em setembro de 2015, a Organização das Nações Unidas (ONU), aprovou um conjunto de metas que vinham sendo elaboradas desde 2012 no âmbito da Conferência das Nações Unidas sobre Desenvolvimento Sustentável (Rio+20): os Objetivos de Desenvolvimento Sustentável (Agenda 2030), contendo 17 objetivos globais e 169 metas para promover a inclusão social, o desenvolvimento sustentável e a governança democrática em todo o mundo entre 2016 e 2030.

A Agenda 2030 é um plano de ação para as pessoas, o planeta e a prosperidade. Ela busca fortalecer a paz universal com mais liberdade, e reconhece que a erradicação da pobreza em todas as suas formas e dimensões, incluindo a pobreza extrema, é o maior desafio global ao desenvolvimento sustentável. Os Objetivos do desenvolvimento Sustentável (ODS) foram 
construídos sobre as bases estabelecidas pelos Objetivos de Desenvolvimento do Milênio (ODM), de maneira a completar o trabalho e responder a novos desafios. São integrados e indivisíveis, e mesclam, de forma equilibrada, as três dimensões do desenvolvimento sustentável: a econômica, a social e a ambiental.

De acordo com os objetivos e metas, são previstas ações mundiais nas áreas de erradicação da pobreza, segurança alimentar, agricultura, saúde, educação, igualdade de gênero, redução das desigualdades, energia, água e saneamento, padrões sustentáveis de produção e de consumo, mudança do clima, cidades sustentáveis, proteção e uso sustentável dos oceanos e dos ecossistemas terrestres, crescimento econômico inclusivo, infraestrutura, industrialização, entre outros. No presente estudo, optou-se por analisar o objetivo número 11,qual seja, tornar as cidades e os assentamentos humanos inclusivos, seguros, resilientes e sustentáveis,e que se subdivide em 10 metas.

Objetivo 11. Tornar as cidades e os assentamentos humanos inclusivos, seguros, resilientes e sustentáveis

11.1 Até 2030, garantir o acesso de todos à habitação segura, adequada e a preço acessível, e aos serviços básicos e urbanizar as favelas

11.2 Até 2030, proporcionar o acesso a sistemas de transporte seguros, acessíveis, sustentáveis e a preço acessível para todos, melhorando a segurança rodoviária por meio da expansão dos transportes públicos, com especial atenção para as necessidades das pessoas em situação de vulnerabilidade, mulheres, crianças, pessoas com deficiência e idosos

11.3 Até 2030, aumentar a urbanização inclusiva e sustentável, e as capacidades para o planejamento e gestão de assentamentos humanos participativos, integrados e sustentáveis, em todos os países

11.4 Fortalecer esforços para proteger e salvaguardar o patrimônio cultural e natural do mundo

11.5 Até 2030, reduzir significativamente o número de mortes e o número de pessoas afetadas por catástrofes e substancialmente diminuir as perdas econômicas diretas causadas por elas em relação ao produto interno bruto global, incluindo os desastres relacionados à água, com o foco em proteger os pobres e as pessoas em situação de vulnerabilidade

11.6 Até 2030, reduzir o impacto ambiental negativo per capita das cidades, inclusive prestando especial atenção à qualidade do ar, gestão de resíduos municipais e outros

11.7 Até 2030, proporcionar o acesso universal a espaços públicos seguros, inclusivos, acessíveis e verdes, 
particularmente para as mulheres e crianças, pessoas idosas e pessoas com deficiência

11.a Apoiar relações econômicas, sociais e ambientais positivas entre áreas urbanas, periurbanas e rurais, reforçando o planejamento nacional e regional de desenvolvimento

11.b Até 2020, aumentar substancialmente o número de cidades e assentamentos humanos adotando e implementando políticas e planos integrados para a inclusão, a eficiência dos recursos, mitigação e adaptação às mudanças climáticas, a resiliência a desastres; e desenvolver e implementar, de acordo com o Marco de Sendai para a Redução do Risco de Desastres 2015-2030, o gerenciamento holístico do risco de desastres em todos os níveis

11.c Apoiar os países menos desenvolvidos, inclusive por meio de assistência técnica e financeira, para construções sustentáveis e resilientes, utilizando materiais locais (UNITED NATIONS, 2015 , p. 21 e 22 ).

Sem o monitoramento e a participação das prefeituras locais no monitoramento, fiscalização e controle, será muito difícil para o país combater esse crime ambiental. Mais um exemplo concreto das cidades como atores centrais no cumprimento das metas brasileiras para o combate ao aquecimento global.

Dessa forma, verifica-se que ODS 11 é o único Objetivo claramente focado em cidades e assentamentos humanos. Por conta disso, priorizou-se a seleção de indicadores com nível de desagregação municipal. Considerou-se útil iniciar o trabalho a partir do Relatório do Desenvolvimento Sustentável na América Latina: seguimento da Agenda das Nações Unidas para o Desenvolvimento Pós-2015 e Rio+20, em particular a seção sobre os temas emergentes, assim como dos relatórios anuais do IBGE, do Ipea e dos diversos ministérios. Todos as metas terão como data de verificação o ano de 2030.

A meta 11.1 é de, até 2030, garantir o acesso de todos a habitação segura, adequada e a preço acessível, e aos serviços básicos e urbanizar as favelas. Cidades mais inclusivas, seguras, sustentáveis e resilientes a desastres ou a eventos incomuns são as metas deste objetivo, conhecido como ODS das cidades. Por isso, um primeiro ponto é a urbanização de favelas.

A meta 11.2 tem o mesmo prazo para verificação, e trata sobre proporcionar o acesso a sistemas de transporte seguros, acessíveis, sustentáveis e a preço acessível para todos, melhorando a segurança rodoviária por meio da expansão dos transportes públicos, com 
especial atenção para as necessidades das pessoas em situação de vulnerabilidade, mulheres, crianças, pessoas com deficiência e idosos.

No que se refere à acessibilidade, a Lei n. 10.098, de 19 de dezembro de 2000, definea como uma [...] possibilidade e condição de alcance para utilização, com segurança e autonomia, dos espaços, mobiliários e equipamentos urbanos, das edificações, dos transportes e dos sistemas e meios de comunicação, por pessoa portadora de deficiência ou com mobilidade reduzida.Como a mobilidade urbana é fundamental para que o indivíduo exerça sua cidadania, a melhoria da oferta de serviços de transporte, com atendimento para todos os tipos de grupos, incluindo os que se encontram em situação de vulnerabilidade, mulheres, pessoas com deficiência e idosos, esse é foco da meta 11.2.

A preservação da cultura (11.4), o fortalecimento dos espaços de participação (11.3), a redução do número de mortes, de pessoas afetadas por catástrofes e de prejuízos (11.5) e a redução dos impactos ambientais pela vida e produção econômica nas cidades complementam as metas deste ODS.

No cenário brasileiro, é imprescindível monitorar o número de governos locais implementando mecanismos de Orçamento Participativo. Vale ressaltar que o Estatuto da Cidade e o Estatuto da Metrópole incluem em suas metodologias de gestão pública e planejamento os princípios de participação, inclusão e integração setorial. Estes são marcos normativos importantes para o país, sobretudo pela quantidade de planos setoriais e pela inexistência de mecanismos de articulação e integração destes.

A meta 11.6 prevê reduzir o impacto ambiental negativo per capita das cidades, inclusive prestando especial atenção à qualidade do ar, gestão de resíduos municipais e outros. Faz referência ao impacto ambiental do sistema de transporte, do residencial e da atividade econômica terciária e industrial das cidades.Cabe ressaltar que investimentos em modernização de infraestruturas e mudanças de comportamento com foco nos princípios de sustentabilidade socioambiental e econômica também podem contribuir diretamente para o cumprimento da mesma.

O acesso universal a espaços seguros, inclusivos, acessíveis e verdes, meta 11.7, apresenta-se com intensa ligação à gestão municipal, porém, no âmbito desta meta, destacamse algumas iniciativas na esfera federal. O Ministério das Cidades tem programas voltados ao planejamento urbano, à reabilitação urbana, à acessibilidade e à prevenção de riscos nos espaços das cidades. Nesse sentido, o Programa Nacional de Reabilitação tem como uma de 
suas principais diretrizes a promoção da funcionalidade e da recuperação de imóveis subutilizados de áreas urbanas centrais a fim de incitar uma maior acessibilidade a esses espaços bem como sua democratização. O Programa atua em três frentes principais: apoio direto utilizando recursos financeiros; disponibilização de imóveis públicos e coordenação setorial e fomento às ações federativas (MINISTÉRIO DAS CIDADES, 2014b).

Ainda, o Estatuto da Cidade (Lei Federal n. 10.257, de 10 de julho 2001) prevê que os municípios com mais de 20 mil habitantes ou que façam parte de regiões metropolitanas devem elaborar planos diretores regularmente, de forma participativa, inclusiva, democrática e sustentável. O Plano Diretor estabelece regras para o crescimento e a organização da cidade (MINISTÉRIO DAS CIDADES, 2014).

Por fim, apresentam-se como objetivos apoiar relações econômicas, sociais e ambientais positivas entre áreas urbanas, periurbanas e rurais, reforçando o planejamento nacional e regional de desenvolvimento (11.a); até 2020, aumentar substancialmente o número de cidades e assentamentos humanos adotando e implementando políticas e planos integrados para a inclusão, a eficiência dos recursos, mitigação e adaptação à mudança do clima, a resiliência a desastres; e desenvolver e implementar, de acordo com o Marco de Sendai $^{2}$ para a Redução do Risco de Desastres 2015-2030, o gerenciamento holístico do risco de desastres em todos os níveis (11.b) e, por fim, apoiar os países menos desenvolvidos, inclusive por meio de assistência técnica e financeira, para construções sustentáveis e resilientes, utilizando materiais locais (11.c).

Pode-se verificar que os ODS, embora de natureza global e universalmente aplicáveis, dialogam com as políticas e ações nos âmbitos regional e local, o que leva à conclusão da importância da participação e engajamento popular nas ações municipais, bem como a necessidade de atores participativos na gestão da coisa pública, com a finalidade de garantir o atingimento da meta 11 dos Objetivos do Desenvolvimento Sustentável. Sendo necessária, na disseminação e no alcance das metas estabelecidas pelos ODS, promover a atuação dos governantes e gestores locais como protagonistas da conscientização e mobilização em torno dessa agenda.

${ }^{2} \mathrm{O}$ Marco de Sendai traz foco maior na redução do risco, ou seja, aborda os fatores causadores do desastre (abordagem preventiva) e está, assim, mais diretamente relacionado às negociações sobre desenvolvimento sustentável e mudança do clima. O Marco de Sendai para a Redução do Risco de Desastre (RRD) também traz novos mecanismos de monitoramento, desde o nível local até o nacional. 
É importante para o bom desenvolvimento do presente estudo analisar os conceitos existentes sobre desenvolvimento sustentável, é o que se passa a fazer.

\section{Dos variados conceitos de desenvolvimento sustentável}

Com relação à definição de sustentabilidade, pode-se afirmar que não se trata de uma definição estanque, uniforme e pacífica. Ao revés, a sustentabilidade apresenta diversas nuances e dimensões, que a traduzem mais como um conjunto de ideias, crenças e atitudes, do que um mero verbete no dicionário. Há quem defenda que o conceito de desenvolvimento sustentável surgiu com o nome de ecodesenvolvimento nos anos 1970 e que foi fruto do esforço para encontrar uma terceira via opcional àquelas que se opunham, de um lado, desenvolvimentistas e, de outro, defensores do crescimento zero. Para estes últimos, chamados de "zeristas" ou (pejorativamente) "neomalthusianos", os limites ambientais levariam a catástrofes se o crescimento econômico não cessasse (ROMEIRO, 2012, p. 65-92).

Para Stuart B. Hill, sustentabilidade refere-se às maneiras de se pensar o mundo e as formas de prática pessoal e social que levam a indivíduos com valores éticos, autônomos e realizados; a comunidades construídas em torno a compromissos coletivos, tolerância e igualdade; culminam em sistemas sociais e instituições participativas, transparentes e justas; e práticas ambientais que valorizam e sustentam a biodiversidade e os processos ecológicos de apoio à vida (HILL, 2003).

O meio ambiente pode ser entendido como o conjunto de riquezas naturais, suscetíveis de exploração econômica. A sustentabilidade enquadra-se como aquela baseada em políticas de desenvolvimento econômico e social, garantindo a todos os membros da sociedade a oferta de serviços, desde que não coloque em risco a viabilidade dos ambientes naturais, artificiais e sociais (ESPADAS, 2007, p. 11).Ao considerarmos que desenvolvimento sustentável é o processo de ampliação permanente das liberdades substantivas dos indivíduos em condições que estimulem a manutenção e a regeneração dos serviços prestados pelos ecossistemas às sociedades humanas (ABRAMOVAY, 2010, p. 97-113), e que ele é formado por uma infinidade de fatores determinantes, mas cujo andamento depende, justamente, da presença de um horizonte estratégico entre seus protagonistas decisivos, concluímos que o que está em jogo nesse processo é o conteúdo da própria cooperação humana e a maneira como, no âmbito dessa cooperação, as sociedades optam por usar os ecossistemas de que dependem. O que nos 
leva a afirmação de que a Educação para o Desenvolvimento Sustentável é indispensável, ao lado de outros instrumentos, para a manutenção do equilíbrio ecológico.

A definição de desenvolvimento sustentável também pode ser encontrada no documento Nosso Futuro Comum, e complementada pelo livro Proteger a Terra: Estratégia para uma Vida Sustentável (Caring for the Earth: A Strategy for Sustainable Living), publicado pela União Internacional de Conservação (UICN), pelo Programa das Nações Unidas para o Meio Ambiente (PNUMA) e pelo Fundo Mundial pela Natureza (WWF), em 1991.

O conceito de desenvolvimento sustentável foi definido como "melhorar a qualidade da vida humana respeitando a capacidade do ecossistema" (WWF, 1991, p. 10). Já o ratificado na Cúpula de Johanesburgo, entende como três os pilares do desenvolvimento sustentável: sociedade, meio ambiente e economia. Nessa linha, a sociedade sintetiza a compreensão das instituições sociais e do papel que desempenham na mudança e no desenvolvimento, assim como nos sistemas democráticos e participativos que dão a oportunidade de expressar opiniões, eleger governos, criar consensos e resolver controvérsias.

O Meio ambiente compreende a consciência dos recursos e da fragilidade do meio ambiente físico e dos efeitos das atividades e decisões humanas sobre o meio ambiente, com o compromisso de incluir as questões ambientais na elaboração das políticas sociais e econômicas. E a Economia abrange a consciência em relação aos limites e ao potencial do crescimento econômico e seus impactos na sociedade e no meio ambiente, com o compromisso reduzir os níveis de consumo individual e coletivo, em relação à preocupação com o meio ambiente e a justiça social.

Essas três áreas - sociedade, meio ambiente e economia - estão interconectadas entre si pela dimensão cultural, uma característica do desenvolvimento sustentável que devemos sempre ter em mente. Mas é importante frisar que todos os conceitos de desenvolvimento sustentável desenvolvimento sustentável apontam para o sentido deque se trata de um conceito dinâmico, reconhece que a sociedade humana está em constante transformação, ou seja, desenvolvimento sustentável não busca preservar o status quo, ao contrário, busca conhecer as tendências e as implicações da mudança.

\section{Relação entre os ODS e as ações municipais}


As metas previstas nos ODS são uma forma de dar parâmetros para os gestores municipais na execução de políticas públicas. O desenvolvimento sustentável é uma escolha que depende dos indicadores que você vai olhar e uma excelência de gestão. É preciso trabalhar com uma agenda que tenha eixos, indicadores, metas, sugestões e apoio de casos exemplares, de referências. Transformando, assim, intenções em ações concretas.

Uma das mais difíceis questões que desafiam o Brasil e tantos outros países é: como equilibrar o desenvolvimento econômico com a sustentabilidade ambiental e a justiça social, por meio de uma governança transparente e democrática? Para a construção desta resposta, não cabem mais escolhas que abordem o problema de forma fragmentada ou parcial - a questão é complexa e deve ser enfrentada de forma sistêmica e horizontal. É necessário e urgente implementar um novo paradigma de desenvolvimento.

Na América Latina, o Brasil é o país mais urbanizado, resultado de um intenso processo de estruturação das cidades iniciado na década de 1950, que provocou a concentração de $85 \%$ de sua população nas áreas urbanas. O crescimento da população que vive nas cidades acarreta novos e complexos desafios para os gestores públicos locais, pressionando a infraestrutura e o consumo dos recursos naturais. Como forma de dar instrumentos aos municípios para enfrentarem essa situação, a Constituição Federal de 1988 instituiu um processo de descentralização das políticas públicas, proporcionando maior protagonismo aos municípios e à participação da sociedade como eixos centrais do período de redemocratização que se consolidava com a Carta Magna.

As prefeituras brasileiras passaram a ser protagonistas nos processos de decisão, ao mesmo tempo em que tiveram de enfrentar problemas relacionados à desigualdade social, à poluição, às dificuldades de mobilidade, ao excesso de resíduos, à falta de saneamento básico, habitações precárias, violência e mudanças climáticas Tais problemas demandaram a criação de um novo modelo de gestão pública, que incluísse planos estratégicos eficientes e equipes bem preparadas para desenvolvê-lo.

Para a elaboração de um planejamento urbano moderno, é necessária uma abordagem sistêmica pautada na sustentabilidade, que seja capaz de captar as interações existentes entre os diferentes campos que interagem no município: econômico, cultural, social, ecológico, tecnológico, tributário, demográfico etc. O plano deverá envolver os diversos órgãos municipais relacionados a esses temas e realizar uma análise integrada das informações. 
O planejamento estratégico baseado em uma abordagem sistêmica e participativa deve considerar, assim, a execução dos projetos sob uma visão de curto, médio e longo prazos, a fim de assegurar a continuidade dos programas, especialmente das obras de infraestrutura, normalmente mais demoradas. Também deve estabelecer metas que possam ser monitoradas publicamente ao longo do tempo. Tais diretrizes devem estar contempladas no Plano Diretor e no Plano Plurianual.

Exigido pela Constituição para municípios com mais de 20 mil habitantes, o Plano Diretor é o instrumento da política de desenvolvimento urbano. Seu principal objetivo é oferecer condições para o desenvolvimento local, ao possibilitar uma compreensão dos fatores políticos, econômicos e territoriais relativos ao município. Os princípios que norteiam o Plano Diretor estão contidos no Estatuto da Cidade, documento no qual o plano está definido como instrumento básico para orientação da política de desenvolvimento e de ordenamento da expansão urbana do município (ESTATUTO DA CIDADE, 2002).

Também determinado pela Constituição Federal, o Plano Plurianual especifica os gastos anuais da administração municipal que serão destinados a obras e projetos estabelecidos no plano de ação governamental ou no Plano Diretor. O PPA deve ser elaborado no primeiro ano de gestão do prefeito eleito, abrangendo o período de quatro anos da gestão municipal, com vigência a partir do segundo ano da administração, até o primeiro ano da gestão posterior.

Diversos são os desafios de gestão nos municípios brasileiros, pois, na medida em que as políticas públicas se tornam complexas, surgem novas diretrizes,e é preciso estabelecer novos marcos regulatórios, novas institucionalidades, e tudo isso obriga os municípios a apresentarem qualificação das pessoas e o desenvolvimento das instituições do local.

Atualmente, a principal norma que rege as políticas públicas para as áreas urbanas é o Estatuto da Cidade (Lei Federal $\mathrm{n}^{\circ}$ 10.257, de 2001). Ele reúne diretrizes gerais e instrumentos urbanísticos, tributários e jurídicos para garantir efetividade ao Plano Diretor, documento responsável pelo estabelecimento da política urbana na esfera municipal e pelo desenvolvimento das funções sociais da cidade e da propriedade urbana. No campo da moradia, a Secretaria Nacional de Habitação do Ministério das Cidades coordenou a elaboração do Plano Nacional de Habitação (PlanHab). A finalidade última dele é universalizar o acesso à moradia digna a todo cidadão. Em 2012, o déficit habitacional no 
Brasil era de aproximadamente 5,8 milhões de moradias. Assim, há grandes esforços que precisam ser conduzidos.

Quanto ao transporte urbano, o país tem diretrizes estabelecidas pela Política Nacional de Mobilidade Urbana (Lei Federal $n^{\circ} 12.587$, de 2012), e entre seus princípios estão a acessibilidade universal e o desenvolvimento sustentável das cidades, e prevê que são atribuições municipais planejar, executar e avaliar as ações em mobilidade, assim como regulamentar serviços de transporte urbano. Já o planejamento para minimizar efeitos de eventos da natureza, como chuvas, vendavais, secas, é orientado pela Política Nacional de Proteção e Defesa Civil, Lei $n^{\circ} 12.608$, de 2012, que estabelece um sistema integrado para o monitoramento e prevenção de riscos em todo o país, afirmando que compete aos municípios coordenar ações de prevenção, identificar, mapear e fiscalizar a ocupação das áreas de risco, incorporar as ações de defesa civil no planejamento municipal, atender as populações afetadas por eventuais desastres ou incidentes. A Secretaria Nacional de Proteção e Defesa Civil, órgão do Ministério da Integração Nacional, é responsável por coordenar as ações no território.

Pode-se verificar que a legislação brasileira correlata aos Objetivos do Desenvolvimento Sustentável, ou seja, as que tratam sobre mobilidade, resiliência, questões ambientais, e outros, delega aos municípios grandes responsabilidade a serem cumpridas, de modo que a escolha do gestor municipal precisa ser realizada com parcimônia, afinal, o alcance dos ODS depende, e muito, das diretrizes que o município tomar.

Mas, como os objetivos globais se transformam em objetivos locais?

Os ODS não são vinculantes, mas são ferramentas de planejamento a médio e longo prazo que viabilizam o alinhamento nacional e subnacional de políticas sociais, ambientais e econômicas.

Ainda, nos dizeres de Haroldo Machado Filho (Assessor Sênior PNUD), utiliza-se o termo "Localização", nesse contexto, entendido como o processo de se levar em consideração os contextos subnacionais na realização da Agenda 2030, desde o estabelecimento de objetivos e metas até a determinação dos meios de implementação, bem como o uso de indicadores para medir e acompanhar o progresso. Localização refere-se, assim, tanto à forma como os governos locais e regionais podem apoiar a realização dos ODS por meio de ações "de baixo para cima", quanto a forma como os ODS podem fornecer um arcabouço para uma política de desenvolvimento local. 
Com relação às modalidades de acompanhamento é indispensável ser estabelecido alguns itens: integração das metas aos planos e políticas locais e adequação dos meios de implementação; Estabelecimento de metas municipais estaduais intermediárias e finais; Recursos e parcerias; Requisitos de dados; Prazos; Participação e coordenação;

Os ODS precisam de ajustes para se tornar objetivos locais efetivos. Algumas dessas conformações relacionam-se com as estratégias setoriais do plano de desenvolvimento local de longo e médio prazo e com a visão do planejamento e orçamento anual.

Outros amoldamentos que precisam ser realizados para se transformar os objetivos globais em locais são: conscientização pública; Abordagem por diversos stakeholders; Revisão de planos e adaptação aos ODS; Coerência política horizontal; Coerência política vertical (do global para o local); Orçamento futuro; Acompanhamento, relatórios e accountability e avaliação de riscos e promoção de adaptação.

Mas, de todas as atitudes que precisam ser tomadas para que os ODS possam ser efetivados no âmbito municipal, a integração detém uma posição de destaque, pois a partir do momento em que diferentes setores podem traçar suas conexões com as diferentes áreas de prioridade local surge uma força fomentadora da implementação dos ODS.

A integração pode se dar processos por meio de decisão política que levam em conta as interdependências entre dimensões e setores (UNDESA, 2015), mas, para isso, há que se priorizar a multidimensionalidade na construção dos planos e políticas públicas, a participação social nas políticas públicas e manter o foco nas interligações e interdependências das regiões e territórios.

\section{PIV (Produto Interno Verde)}

Entrou em vigor, dia 17 de outubro de 2017, a lei federal número 13.493, a qual trata da criação do Produto Interno Verde (PIV), novo tipo de índice que mede o desenvolvimento sustentável no país, do qual o cálculo considerará o patrimônio ecológico nacional, inovando, por conseguinte, no conceito de governança ambiental.

O conceito de Produto Interno Bruto (PIB) ainda é principal indicador mundial do nível da atividade econômica de um país, expressando o valor da produção de bens e serviços realizados em um determinado período. Contudo, falta um aspecto ambiental quando se trata 
desse índice, falta uma hodierna visão, calcada sob a perspectiva desenvolvimento sustentável.

A ONU (Organização das Nações Unidas), em 2012, durante a Rio+20, apresentou o conceito de "PIB Verde", com a finalidade principal de estabelecer uma padronização metodológica do sistema de avaliação da atividade econômica, tendo em vista os interesses e necessidades de melhoria do meio ambiente, incluindo nessa mensuração novos parâmetros socioambientais a serem observados e aferidos pelos diversos países.

Desta forma, o legislador pátrio criou em momento uma nova forma oficial para se aferir o adequado nível de desenvolvimento e os novos objetivos da atividade produtiva, levando agora em consideração a consciência e a necessidade de observância para construção e sustentabilidade.

A lei é pequena, se considerar apenas a quantidade de artigos, apenas três, mas de grande impacto econômico e socioambiental. Vejamos:

Art. $1^{\circ} \mathrm{O}$ órgão federal responsável pelo cálculo do Produto Interno Bruto (PIB) divulgará também, se possível anualmente, o Produto Interno Verde (PIV), em cujo cálculo será considerado, além dos critérios e dados tradicionalmente utilizados, o patrimônio ecológico nacional.

Art. $2^{\circ} \mathrm{O}$ cálculo do PIV levará em consideração:

I - iniciativas nacionais e internacionais semelhantes;

II (VETADO).

$\S 1^{\circ} \mathrm{O}$ cálculo do PIV deverá possibilitar a convergência com sistemas de contas econômicas ambientais adotados em outros países, permitindo sua comparabilidade.

$\S 2^{\circ}$ A metodologia para o cálculo do PIV deverá ser amplamente discutida com a sociedade e as instituições públicas, incluindo o Congresso Nacional, antes de um sistema de contas econômicas ambientais ser oficialmente adotado no Brasil.

Art. $3^{\circ}$ Esta Lei entra em vigor na data de sua publicação. 
$\mathrm{O}$ veto presidencial foi exercido neste caso, no inciso II, do artigo $2^{\circ}$. Originalmente constava do texto: "II - o Índice de Riqueza Inclusiva (IRI), elaborado pela Organização das Nações Unidas (ONU).". As razões do veto foram apresentadas na mensagem $\mathrm{n}^{\circ}$ 407, de 17 de outubro de 2017, (CÂMARA LEGISLATIVA, 2017) dirigida ao Presidente do Senado Federal.

O presidente fundamentou o veto parcial por existir, no inciso II, “contrariedade ao interesse público". Apresenta-se o inteiro teor das razões do veto:

"O Índice de Riqueza Inclusiva (IRI) é um índice sintético, caracterizando-se não como uma estatística, mas como um modelo de avaliação estruturado sobre determinado quadro conceitual e, como tal, não recomendado como parte de um conjunto de estatísticas oficiais. Ademais, sua eventual adoção dificultaria o melhor aproveitamento, determinado pelo projeto de lei, de outras iniciativas nacionais e internacionais, ou a convergência com sistemas de contas econômicas ambientais adotados em outros países, que permitirão a comparabilidade do PIV".

Essas, Senhor Presidente, as razões que me levaram a vetar o dispositivo acima mencionado do projeto em causa, as quais ora submeto à elevada apreciação dos Senhores Membros do Congresso Nacional.

O Índice de Riquezas Exclusivas (IRI), vetado na lei apresentada, é formado pela industrialização e pelo capital humano, natural e social do país. O IRI considera quatro fatores para estabelecer se um país cresce de maneira sustentável. O primeiro deles é o capital humano, que mede o nível de educação e capacitação da população; o segundo é o capital produtivo, que mede a capacidade manufatureira do país; o terceiro é o capital natural, que diz das florestas, peixes, combustíveis fósseis, minerais e terra agrícola dos países; e o capital social, que calcula reduções na expectativa de vida dos habitantes ao longo do tempo.

\section{CONCLUSÕES}


Os Objetivos do Desenvolvimento Sustentável surgiram da necessidade de estipular metas, com o ambicioso objetivo de reduzir a desigualdade social, ampliar o acesso à água potável, garantir que tenhamos uma sadia qualidade de vida, entre tantos outros direitos. Embora o acordo tenha sido firmado entre 193 Estados-membros da ONU, é evidente que as políticas públicas a serem realizadas se encontram nos níveis globais e locais. Assim, os ODS, embora de natureza global e universalmente aplicáveis, dialogam com as políticas e ações nos âmbitos regional e local.

A governança revela-se primordial para a disseminação e alcance das metas estabelecidas pelos ODS, sendo preciso promover a atuação dos governantes e gestores locais como protagonistas da conscientização e mobilização em torno dessa agenda. Em relação à legislação brasileira correlata aos ODS, como exposto no decorrer do presente estudo, incumbe aos municípios responsabilidade em diversas áreas de atuação, como por exemplo, nos quesitos de mobilidade e resiliência das cidades. Porém, sabe-se que os municípios com os menores Índices de Desenvolvimento Humano Municipal (IDHM) são os que necessitam de mais apoio para aderirem e aplicarem os ODS à sua gestão cotidiana. Isso porque ainda é preciso fortalecer suas capacidades institucionais para a construção de políticas públicas efetivas e entrega de melhores serviços públicos.

Por outro lado, prefeituras com maiores IDHM e com experiências de implementação dos ODM são exemplos e potenciais parceiras no processo de adoção dos ODS. Os Estados, o Distrito Federal e a União também podem promover políticas para induzir a adoção dos ODS pelos municípios, afim de que sejam incorporados nas agendas nos diferentes níveis federativos.

Tecemos algumas indicações com a finalidade de cumprir a meta 11, e suas subdivisões: é fundamental equilibrar ambição e realismo para a definição de metas locais, evitando a frustração por não atingir objetivos ou a paralisia, pela adoção de ações tímidas; A agenda local precisa ser compatível com as realidades técnica, financeira e política; É aconselhável o alinhamento da agenda política do município com a agenda dos ODS, caso contrário, ações díspares poderão levar a efeitos contraditórios; incluir metas finais e intermediárias no Plano Plurianual (PPA) e no orçamento municipal contribui para a institucionalização dos ODS e adotar os ODS como referência para o planejamento das ações públicas, orientando-as a partir de uma agenda com objetivos, metas, indicadores, políticas e recursos definidos para atingir o desenvolvimento implica buscar a melhoria significativa da qualidade de vida da população. 
Desta forma, as ações municipais se mostraram intrinsicamente ligadas ao atingimento das metas dos Objetivos do Desenvolvimento Sustentável, pois é por meio delas que serão escolhidos os líderes regionais que terão relevante papel no cumprimento e na tomada de decisões visando à sustentabilidade e à equidade intergeracional.

\section{REFERÊNCIAS}

ABRAMOVAY, Ricardo. Desenvolvimento sustentável: qual a estratégia para o Brasil?. Novos estud. - CEBRAP, São Paulo , n. 87, July 2010. Disponível em: $<$ http://www.scielo.br/scielo.php?script=sci_arttext\&pid==iso>. Acesso em $22 \mathrm{de}$ Nov de 2017.

BOFF, Leonardo. Ética e moral: a busca dos fundamentos. Petrópolis: Vozes, 2003.

BRASIL. Constituição (1988). Constituição da República Federativa do Brasil: promulgada em 5 de outubro de 1988. Brasília, DF: Senado, 1988. Disponível em <http://www.planalto.gov.br/ccivil_03/Constituicao/Constituicao.htm>. Acesso em 22 de Nov de 2017.

BRASIL. Lei da Política Nacional do Meio Ambiente. Lei n. 6.938, de 31 de agosto de 1981. Brasília: Presidência da República, 1981. Disponível em: <http://www.planaltogov.br/ccivil_03/leis/L6938compilada.htm>. Acesso em 22 de Nov de 2017.

BRASIL. Lei do Produto Interno Verde. Lei n. 13.493, de 17 de outubro de 2017. Brasília: Presidência da República, 1981. Disponível em: < http://www.planalto.gov.br/ccivil_03/_ato2015-2018/2017/lei/L13493.html>. Acesso em 22 de Nov de 2017

CAPRA, Fritojf. O ponto de mutação: a ciência, a sociedade e a cultura emergente. Tradução de Álvaro Cabral. São Paulo: Cultrix, 1982. Pref. E cap. I: Crise e transformação.

CARSON, Rachel Louis. Primavera silenciosa. Tradução de Raul de Polillo São Paulo: Melhoramentos, 1962. (Série Hoje e amanhã).

ESPADAS, Cejas Juan. Avances em La mejora de La sostenibilidad ambiental urbana em El marco Del nuevo estatuto de autonomia para Andalucía. In: Bravo, Álvaro Sanchez. Ed. Ciudades, Medioambiente e Sostenibilidad. Sevilla: ArCibel, 2007.

HILL, Stuart B.; WILSON, S. and WATSON, K. Learning Ecology: a new approach to learning and transforming ecological consciousness; experiences from social ecology in Australia, In: O'Sullivan. E; Taylor, M. (Eds).TransformingPractices: learningtowardsecologicalconsciousness. New York: Palgrave Press, 2003.

LEFF, Enrique (Coord.). A Complexidade Ambiental. São Paulo: Cortez, 2003.

MINISTÉRIO DAS CIDADES. Programa Brasileiro de Acessibilidade Urbana. 2006. Disponível em: <http://www.cidades.gov.br/images/ /Biblioteca/BrasilAcessivelCaderno02.pdf>. Acesso em 22 de Nov de 2017. 
Campanha Plano Diretor. 2014. Disponível em: <http://www.cidades.gov.br/index.php/planejamento-urbano/350-campanha-planodiretor.html>. Acesso em 22 de Nov de 2017.

. Plano Nacional de Habitação (PlanHab). 2014a. Disponível em: $<$ http://www.cidades.gov.br/index.php/plano-nacional-de-habitacao.html >. Acesso em $22 \mathrm{de}$ Nov de 2017.

Reabilitação urbana. 2014b. Disponível em: <http://www.cidades.gov.br/index.php/reabilitacao-de-areas-urbanas-centrais/902presentacao.html>. Acesso em 22 de Nov de 2017.

MRE. Ministério das Relações Exteriores. Agenda 2030 para o desenvolvimento sustentável. $2016 . \quad$ Disponível em $<$ http://www.itamaraty.gov.br/index.php?option=com\&view=article\&id=135\&catid=101\&Ite mid=433\&lang=pt-BR>. Acesso em 22 de Nov de 2017.

PNUD. Programa das Nações Unidas para o Desenvolvimento. Os objetivos de desenvolvimento do milênio. Disponível em http://www.pnud.org.br/ODM.aspx. Acesso em 22 de Nov de 2017.

ROMEIRO, Ademar Ribeiro. Desenvolvimento sustentável: uma perspectiva econômicoecológica. Estud. av., São Paulo, v.26, n.74, p.65-92, 2012. Disponível em: <http://www.scielo.br/scielo.sci_arttext\&pid\&lng=en\&nrm=iso>. Acesso em 22 de Nov de 2017.

UN.United Nations.The SustainableDevelopmentGoalsReport, 2016.Disponível em: https://nacoesuidas.org/p-The_Sust_Development_Report_2016.pdf. Acesso em 22 de Nov de 2017.

UN.United Nations.A/RES/70/1 - Resolutionadoptedbythe General Assembly on 25 September 2015, 2015. Disponível em: http://www.un.org/ga/search/view_doc.asp?symbol=A/RES/70/1\&Lang=E. Acesso em 22 de Nov de 2017. 